\section{Qualidade de vida, gestão do trabalho e plano de carreira como tecnologista em saúde na atenção básica do Sistema Único de Saúde em São Paulo, Brasil}

\author{
Quality of life, work management, and career \\ planning as a primary care technology in the \\ Unified National Health System in \\ São Paulo State, Brazil
}

Francisco Antonio de Castro Lacaz 1 Nelson Passagem Vieira 1 Carlos Tato Cortizo ${ }^{2}$ Virgínia Junqueira 2 Ana Paula Lopes dos Santos 1 Fabio Souza Santos 2

\section{Introdução}

\footnotetext{
${ }^{1}$ Escola Paulista de Medicina, Universidade Federal de São Paulo, São Paulo, Brasil.

2 Instituto de Saúde,

Secretaria de Estado da Saúde de São Paulo, São Paulo, Brasil.

Correspondência

F. A. C. Lacaz

Departamento de Medicina Preventiva, Escola Paulista de Medicina, Universidade Federal de São Paulo.

Rua Botucatu 740, São Paulo, SP 04023-062, Brasil.

franlacaz@hotmail.com
}

\begin{abstract}
This article discusses the concept of quality of life in and at work, linked to health work management based on the evaluation of a work management instrument: the Career, Job, and Wage Plan. The aim was to analyze the plan as a work management technology in primary care in the Unified National Health System (SUS). The article discusses the plan in three municipalities in São Paulo State, Brazil: São Paulo, Guarulhos, and Campinas, in compliance with guidelines issued by the National Health Council in 2006, and using a qualitative survey conducted in 2007-2008. The study presents the findings from research in eight municipalities, based on interviews with managers, users (represented by Health Councils), and health workers and health sector trade unionists. The article concludes that this is still an incipient public management policy issue, with limited command by users, trade unionists, and health workers in the target municipalities, heavily populated "hub cities" in the health regions.
\end{abstract}

Quality of Life; Labor Relations; Single Health System
Ao se discutir a qualidade de vida no/do trabalho, é importante assinalar a historicidade do conceito ao transitar pelos anos 1960 do século passado aos anos 2000 do novo século. Na verdade essa temática surge no final dos anos 1950, relacionando-se com experiências de trabalho vivenciadas por trabalhadores na perspectiva de uma produtividade por eles regulada 1 .

Já nos anos 1970, qualidade de vida no/do trabalho relacionava-se com a busca pela melhoria de condições, ambientes, organização do trabalho, visando à maior satisfação e produtividade. Essa visão é influenciada por um movimento originado a partir do "chão de fábrica” especialmente na Europa, no qual a "gestão participativa" e a "democracia industrial” são ideais a serem conquistados e garantidos. E é justamente influenciada por essa realidade que, em meados dos anos 1970, mais precisamente em 1976, a Organização Internacional do Trabalho (OIT) lança o Programa Internacional para o Melhoramento das Condições de Trabalho (PIACT), que preconizava a melhoria geral de vida como aspiração da humanidade, melhoria esta que não pode ser barrada no portão da fábrica, que tinha como pressuposto a participação dos trabalhadores nas decisões relativas à sua vida e às suas atividades laborais 2,3,4.

A partir dos anos 1980, o enfoque da globalização passa a influenciar a visão de qualidade 
de vida no/do trabalho, quando busca dar conta de questões relacionadas à produtividade, mas agora articulada com a qualidade do produto e a competitividade, o que envolve a motivação, o pertencimento à empresa como algo intrínseco à produção capitalista, ao que se soma a saúde no trabalho, considerando aspectos relativos a formas diferenciadas de organização do trabalho e a novas tecnologias de gestão do trabalho. Tal enfoque vai ser a tônica também dos anos 1990 e 2000.

De certa forma, a relevância dessa temática relaciona-se ao esgotamento da organização do trabalho taylorista/fordista que se associa ao aumento do absenteísmo, ao mal estar no trabalho e a não aderência dos trabalhadores às metas definidas pela gerência 5 .

Agora, o modelo japonês, calcado na experiência da Toyota, o toyotismo, é o novo paradigma de organização do trabalho a ser implantado 6,7.

Aqui, o enfoque da qualidade de vida no/do trabalho relacionada à saúde no trabalho, será discutido com base nas contribuições do campo de práticas e conhecimentos Saúde do Trabalhador 8,9 , na medida em que permite pensar numa abordagem mais holística a respeito desta relação, mediada pela categoria processo de trabalho, conceito central apreendido pelo campo, e que vai possibilitar uma explicação mais aprofundada do quadro de morbi-mortalidade ligado ao trabalho na contemporaneidade, em que as doenças relacionadas ao trabalho apresentam um novo perfil de ocorrência pelo predomínio dos distúrbios mentais, das doenças psicossomáticas e cardiocirculatórias 1,10 .

Frise-se que o conceito de processo de trabalho articula objeto de trabalho, instrumentos de trabalho e o próprio trabalho e sua gestão considerando as formas históricas e peculiares de organização 11,12,13.

A possibilidade de adoção da categoria processo de trabalho aplicado à saúde remete à formulação da Saúde Coletiva, que define como objeto do processo de trabalho em saúde o processo saúde-doença, associado à noção de problemas de saúde, isto é, circunstâncias que interferem naquele processo, cujo enfrentamento pode ser de caráter ocasional ou contínuo, como propõe a vigilância em saúde 14,15.

Ademais, falar em processo (e gestão) de trabalho em saúde remete ao conceito de necessidades em saúde 16 envolvendo: condições de vida; acesso às tecnologias de saúde; estabelecimento de vínculos entre equipes/profissionais de saúde e usuários; e a autonomia da clientela. Remete, ainda, às tecnologias em saúde, ou seja, conhecimentos aplicados visando à saúde individual e coletiva, o que diz respeito a máquinas e equipamentos médicos, as chamadas tecnologias duras; aos protocolos, as tecnologias levesduras; e às relações intersubjetivas, as tecnologias leves 17 .

Franco 18, ao dialogar com as formulações de Mehry 17, introduz a noção de composição técnica do trabalho em saúde, na qual busca articular o trabalho morto, expresso majoritariamente nas tecnologias duras (e leves-duras), com o trabalho vivo que predomina nas atividades da atenção básica em saúde 19,20. A composição técnica do trabalho é também determinada pela implicação do trabalhador de saúde com seu próprio trabalho na perspectiva de torná-lo mais significativo, implicação esta que pode ajudar na busca do vínculo e da autonomia 18 .

Nesse emaranhado de relações também pontifica a micropolítica que envolve o papel protagônico dos trabalhadores e usuários dos serviços de saúde nos espaços relacionais de trabalho, o qual é orientado por interesses diversos que organizam as práticas e ações de saúde, particularmente na atenção básica em saúde. Salientese que o espaço da micropolítica é múltiplo em função das várias identidades existentes, de seus projetos, espaço este onde se define o perfil da atenção em saúde e das tecnologias nela incorporadas. Implicada também nessas relações que configuram a composição técnica do trabalho está a idéia de subjetividade, aqui caracterizada como o modo próprio de ser e atuar no mundo e na relação com o outro. Trata-se de algo dinâmico e que muda com a experiência acumulada. É influenciada pelos valores e cultura construídos ao longo do tempo sendo, portanto, socialmente produzida e estando em constante mutação, dado que a história e as experiências de vida, bem como as relações com os outros, vão conformando processos de subjetivação, moldados especialmente pelo trabalho como experiência que transforma e produz novas formas de entender e agir no mundo e com o outro, realidade esta particularmente presente nas atividades no setor de serviços 10 .

Quando se procura articular qualidade de vida no/do trabalho com questões relacionadas à gestão do trabalho, assumem relevância as tecnologias e seu impacto para a saúde; o bem-estar no trabalho que se relaciona diretamente com o nível salarial; a criatividade, a autonomia, ou seja, o grau de controle e poder que o coletivo de trabalhadores tem sobre as condições, ambientes e organização de seu próprio trabalho ${ }^{21}$. A isso se soma a possibilidade de gestão participativa real a qual está vinculada a espaços negociais entre trabalhadores e gestores, à discussão democrática e coletiva visando superar a abordagem de cunho individual dos programas de qualidade 
de vida no trabalho e a "gestão participativa" de iniciativa da própria gerência ligada à intensificação do trabalho e à precarização dos contratos, relações e direitos no trabalho.

Do ponto de vista da gestão do trabalho em saúde no Sistema Único de Saúde (SUS) e sua relação com a qualidade de vida no/do trabalho, advoga-se aqui a importância dos Planos de Carreiras, Cargos e Salários (PCCS), os quais preconizam a capacitação e educação permanente; mesas de negociação para subsidiar o processo decisório e de representação; formas de contratação e ingresso, progressão, fixação e critérios de avaliação de desempenho 20,22.

\section{Material e métodos}

O presente artigo discute - baseando-se em resultados de pesquisa denominada Avaliação da Gestão do Trabalho como Tecnologia em Saúde na Atenção Básica do Sistema Único de Saúde no Estado de São Paulo 21, que teve por base oito municípios do Estado de São Paulo, Brasil (Amparo, Campinas, Guarulhos, Marília, Ribeirão Preto, Santos, São José dos Campos e São Paulo) a relação entre qualidade de vida no/do trabalho na atenção básica e a adoção de PCCS enquanto tecnologia de gestão do trabalho.

No que se refere ao método, foram entrevistados gestores, representantes de usuários nos Conselhos Municipais de Saúde e sindicalistas representantes de trabalhadores da saúde nos oito municípios, ao lado de se proceder à análise dos PCCS existentes, tendo como referência matriz aprovada pelo Conselho Nacional de Saúde em 2006, conforme a Tabela 1.

Dos oito municípios estudados, apenas três tinham PCCS aprovados após 2006, a saber: Campinas, Guarulhos e São Paulo.

Analisando-se a Tabela 1, observa-se que a mesma incorpora aspectos fundamentais para se pensar a qualidade de vida no/do trabalho, em conformidade com o que foi apontado na Introdução, quais sejam: forma de ingresso mediante concurso público; gestão partilhada da carreira entre gestores e trabalhadores; programa institucionalizado de qualificação na perspectiva da educação permanente; programa de avaliação do desempenho; compromisso solidário pela qualificação dos serviços de saúde; possibilidade de equivalência e mobilidade funcional pelas três esferas de governo; critérios de progressão e promoção; e plano de desenvolvimento de pessoal 22 .

Se a potencialidade dos PCCS como instrumento de regramento da vida funcional dos trabalhadores do SUS já era preconizada na pró- pria Lei $n^{o} .8 .080^{23}$, a pesquisa base deste artigo demonstra que tal estratégia não foi adotada de forma cabal, na medida em que dos oito municípios analisados somente três adotaram tal procedimento. Mesmo quando adotado o PCCS, várias lacunas foram observadas conforme será assinalado nos resultados apresentados no próximo item. Frise-se que a existência dos PCCS era um pressuposto para a assinatura do Pacto pela Saúde.

\section{A análise crítica dos PCCS como tecnologia de gestão do trabalho visando à qualidade de vida no trabalho}

O levantamento de informações que possibilitou a análise da gestão do trabalho na atenção básica em saúde nos oito municípios paulistas, objeto do estudo que originou o artigo, as quais estão sistematizadas nas tabelas a seguir, permitiu constatar que quatro deles dispõem do PCCS, sendo que em Campinas 24, Guarulhos 25 e São Paulo 26 há planos posteriores à divulgação das diretrizes nacionais em 2006. Amparo tem plano de carreira que data de 2003.

Tais diretrizes visam à garantia da eqüidade de oportunidades de desenvolvimento profissional, associando evolução funcional a um sistema permanente de qualificação. Para tanto estabelecem um conjunto de princípios, o que serviu de referência para a análise dos PCCS dos diferentes municípios a saber: (i) universalidade dos planos de carreira, ou seja, deve abarcar todos os trabalhadores do SUS; (ii) equivalência dos cargos ou empregos (correspondência dos cargos criados nas três esferas do governo); (iii) concurso público como única forma de ingresso; (iv) mobilidade (possibilidade de trânsito do trabalhador nas diferentes esferas de governo); (v) flexibilidade (possibilidade de adequação dos planos às necessidades e dinâmica do SUS); (vi) gestão partilhada de carreira como garantia de participação dos trabalhadores na formulação e gestão do respectivo plano de carreira; (vii) carreiras como instrumento de gestão (o plano deve se constituir num instrumento gerencial de política pessoal, integrado ao planejamento e desenvolvimento organizacional); (viii) educação permanente (necessidade de oferta permanente de educação aos trabalhadores do SUS); (ix) avaliação do desempenho (entendido como um processo pedagógico focado no desenvolvimento profissional e institucional) e; (x) compromisso solidário, em prol da qualidade dos serviços, do profissionalismo e da adequação técnica do profissional às necessidades do serviço de saúde. 
Diretrizes nacionais para instituição de Plano de Carreiras, Cargos e Salários no âmbito do Sistema Único de Saúde (PCCS-SUS).

\begin{tabular}{|c|c|}
\hline Princípios (PCCS-SUS) & Diretrizes (PCCS-SUS) \\
\hline Ano de publicação & 2006 \\
\hline Universalidade & Todos os trabalhadores \\
\hline Concurso público & Única forma de ingresso \\
\hline Gestão partilhada de carreira & Comissão paritária de carreira (formulação e gestão) \\
\hline Educação permanente & Programa institucional de qualificação \\
\hline Avaliação de desempenho & Programa institucional de avaliação de desempenho \\
\hline Compromisso solidário & Pela qualidade do serviço \\
\hline Flexibilidade & Adequação à dinâmica do SUS \\
\hline Equivalência & Nas três esferas de governo \\
\hline Mobilidade & Nas três esferas de governo \\
\hline Cargos/Empregos & I. Assistente em saúde (Educação básica), II. Especialista em saúde (Ensino Superior) \\
\hline Classes & $\begin{array}{l}\text { I. A (Fundamental incompleto), B (Fundamental completo), C (Ensino Médio completo) e } \\
\text { D (Nível técnico); II. E (Superior completo), F (Especialista/residente), } \\
\text { G (Mestrado) e H (Doutorado) }\end{array}$ \\
\hline Progressão & Mérito e tempo de serviço \\
\hline Promoção & Interstício e formação/Experiência profissional \\
\hline
\end{tabular}

Fonte: Secretaria de Gestão do Trabalho e Educação na Saúde, Ministério da Saúde 22.

Particularmente em relação à gestão partilhada de carreira, as diretrizes preconizam a constituição de comissões paritárias de carreira, com o intuito de propor um anteprojeto de lei do PCCS, que permita acompanhar e avaliar, periodicamente, a implantação dos planos e propor ações para o aperfeiçoamento dos mesmos, visando adequá-los à dinâmica do SUS. Quanto à organização das carreiras, estabelecem um modelo que prevê carreiras amplas, congregando uma vasta gama de funções ou especialidades profissionais. Os cargos previstos são: (i) assistente em saúde, para profissionais de nível de educação básica, completo ou incompleto, profissionalizante ou não e; (ii) especialista em saúde, com nível de escolaridade mínimo correspondente ao Ensino Superior.

A análise da incorporação das diretrizes nacionais nos PCCS municipais está centrada em São Paulo, Campinas e Guarulhos, já que estes possuem planos elaborados após 2006 e, desta maneira, deveriam pautar-se pelas diretrizes nacionais do PCCS-SUS 22.

São Paulo e Guarulhos elaboraram PCCS destinados exclusivamente aos trabalhadores do SUS, enquanto Campinas (e Amparo) aprovaram planos que englobam trabalhadores de outros setores da prefeitura.

As Tabelas 2, 3 e 4 referem-se aos PCCS dos municípios de Guarulhos, São Paulo e Campinas, respectivamente.
Quanto ao vínculo de trabalho daqueles contemplados pelos PCCS, é estatutário em São Paulo e Campinas e pelo regime da Consolidação das Leis do Trabalho (CLT) em Guarulhos. Nos três municípios abarcam trabalhadores de todos os níveis de escolaridade e prevêem o concurso público como única forma de ingresso na carreira.

Por sua vez, os aspectos previstos nas diretrizes nacionais mais diretamente relacionados à democratização das relações de trabalho foram assim colocados nesses PCCS: a gestão partilhada de carreira, a ser concretizada nas comissões paritárias, não se efetivou. Enquanto as diretrizes consideram necessária a politização do processo de construção dos PCCS, os municípios tratam-no como uma questão técnica, a ser resolvida no âmbito gerencial, com contratação de assessorias especializadas. Nos três municípios, o pré-projeto do PCCS constituiu-se numa iniciativa unilateral do gestor, a qual posteriormente foi apresentada à discussão com o conjunto de trabalhadores. Em Campinas, foi criada uma Comissão Técnica de Gestão de Carreiras, com representantes exclusivos dos gestores. Não se criaram nesses municípios as comissões paritárias de carreira, conforme previsto nas diretrizes nacionais com o objetivo de acompanhar e avaliar a implantação dos planos.

Outro aspecto central é o que diz respeito à configuração dos cargos, visto que a homogeneidade e compatibilidade dos cargos nas di- 
Diretrizes do Plano de Carreiras, Cargos e Salários no âmbito do Sistema Único de Saúde (PCCS-SUS), do Município de Guarulhos, São Paulo, Brasil, 2008.

\begin{tabular}{|c|c|}
\hline Princípios (PCCS-SUS) & Diretrizes (Guarulhos) \\
\hline Ano de implantação & 2008 \\
\hline Universalidade & Somente os regidos pela CLT no âmbito do SUS \\
\hline Concurso público & Única forma de acesso \\
\hline Gestão partilhada de carreira & Sem menção específica \\
\hline Educação permanente & $\begin{array}{l}\text { Programa de qualificação profissional controlado pela Secretaria de Saúde; } \\
\text { há menções à formação de gerências e ensino a distância }\end{array}$ \\
\hline Avaliação de desempenho & $\begin{array}{l}\text { Programa de avaliação de desempenho; há menção a indicadores de desempenho do } \\
\text { servidor e avaliação } 360 \text { graus }\end{array}$ \\
\hline Cargos/Empregos & $\begin{array}{l}\text { Nível fundamental: I. Agente de serviços de saúde; II. Auxiliar em saúde; Nível médio: } \\
\text { I. Auxiliar de consultório dentário; II. Condutor de veículos de urgência; III. Técnico de } \\
\text { saúde; IV. Técnico de diagnósticos; V. Rádio operador; VI. Oficial de controle animal; } \\
\text { VII. Prático em farmácia; Nível superior: I. Cirurgião dentista; II. Biomédico; } \\
\text { III. Enfermeiro; IV. Enfermeiro da família; V. Especialista em saúde (fisioterapeuta, } \\
\text { fonoaudiólogo, psicólogo, assistente social etc.); VI. Farmacêutico; VII. Médico; } \\
\text { VIII. Médico da família; IX. Médico veterinário; X. Médico substituto }\end{array}$ \\
\hline Classes & $\begin{array}{c}\text { Nível fundamental: } 2 \text { classes (uma com } 10 \text { e outra com } 15 \text { graus); Nível médio: } 2 \text { classes } \\
\text { (uma com } 10 \text { e outra com } 15 \text { graus); Nível superior: } 3 \text { classes (uma com 7, outra com } 13 \\
\text { e outra com } 15 \text { graus) }\end{array}$ \\
\hline Progressão & Progressão horizontal bianual por merecimento (de acordo com avaliação) \\
\hline Promoção & Progressão vertical mediante avaliação de desempenho e titulação \\
\hline Gratificações & Difícil acesso, difícil provimento, urgência e vigilância sanitária \\
\hline Produtividade e desempenho & $\begin{array}{l}\text { Prêmio de incentivo por metas de contrato de gestão, mediante os critérios: (i) metas; } \\
\text { (ii) desempenho da equipe; (iii) redução do absenteísmo na unidade }\end{array}$ \\
\hline
\end{tabular}

CLT: Consolidação das Leis do Trabalho.

Fonte: Guarulhos 25.

Tabela 3

Diretrizes do Plano de Carreiras, Cargos e Salários no âmbito do Sistema Único de Saúde (PCCS-SUS), do Município de São Paulo, Brasil, 2008.

\begin{tabular}{|c|c|}
\hline Princípios (PCCS-SUS) & Diretrizes (São Paulo) \\
\hline Ano de implantação & 2008 \\
\hline Universalidade & Somente efetivos (níveis médio e superior) no âmbito exclusivo do SUS \\
\hline Concurso público & Única forma de ingresso \\
\hline Gestão partilhada de carreira & Sem menção específica \\
\hline Educação permanente & Sem menção específica \\
\hline Avaliação de desempenho & Sem menção específica \\
\hline Cargos/Empregos & $\begin{array}{l}\text { Nível médio: I. Auxiliar técnico em saúde (autópsia, consultório dentário, citologia } \\
\text { etc.); II. Técnico em saúde (farmácia, laboratório, nutrição etc.); III. Especialista em } \\
\text { saúde (biologia, biomédica, odontologia, fisioterapia, psicologia etc.); Nível superior: } \\
\text { IV. Especialista em saúde - médico }\end{array}$ \\
\hline Classes & $\begin{array}{c}\text { Nível médio: } 2 \text { classes (um deles com } 10 \text { e outro com } 5 \text { categorias); Nível superior: } 3 \\
\text { classes (com } 5 \text { categorias) }\end{array}$ \\
\hline Progressão & Desempenho, tempo carreira, capacitação, atividades \\
\hline Promoção & Desempenho, títulos, atividades - insterstício de 2 anos para progressão e promoção \\
\hline Produtividade e desempenho & $\begin{array}{l}\text { Prêmio de até } 100 \% \text { para médicos; até } 30 \% \text { para outros profissionais de níveis superior } \\
\text { e médio; até } 20 \% \text { para os demais profissionais }\end{array}$ \\
\hline
\end{tabular}

Fonte: São Paulo 26. 
Diretrizes do Plano de Carreiras, Cargos e Salários no âmbito do Sistema Único de Saúde (PCCS-SUS), do Município de Campinas, São Paulo, Brasil, 2007

\begin{tabular}{|c|c|}
\hline Princípios (PCCS-SUS) & Diretrizes (Campinas) \\
\hline Ano de implantação & 2007 \\
\hline Universalidade & Abarca todos os níveis e não é exclusivo do SUS \\
\hline Concurso público & Única forma de acesso \\
\hline $\begin{array}{l}\text { Gestão partilhada de } \\
\text { carreira }\end{array}$ & Comissão técnica de gestão de carreiras (composta por gestores) \\
\hline Educação permanente & Sem menção específica \\
\hline $\begin{array}{l}\text { Avaliação de } \\
\text { desempenho }\end{array}$ & Sistema de avaliação de desempenho \\
\hline Cargos/Empregos & Organizado por profissões ou especialidades \\
\hline Progressão horizontal & $\begin{array}{l}\text { Aptos aqueles que não tiverem suspensão nos últimos } 3 \text { anos, interstício de } 3 \text { anos e } \\
\text { desempenho acima da média do grupo }\end{array}$ \\
\hline Progressão vertical & $\begin{array}{c}\text { Aptos aqueles que não tiverem suspensão nos últimos } 3 \text { anos, interstício de } 3 \text { anos e } \\
\text { desempenho acima da média do grupo (com nota superior a 7) }\end{array}$ \\
\hline $\begin{array}{l}\text { Produtividade e } \\
\text { desempenho }\end{array}$ & $\begin{array}{c}\text { Prêmio produtividade: procedimentos executados, padrão de atendimento, localização } \\
\text { da unidade e tipo de instalação; gratificação de autoridade sanitária para aqueles com } \\
\text { dedicação exclusiva; toda gratificação ou complementação deve ser aprovada pelo } \\
\text { Conselho Municipal de Saúde }\end{array}$ \\
\hline
\end{tabular}

Fonte: Campinas 24 .

ferentes esferas do poder público são condição necessária para a efetivação dos princípios da equivalência e mobilidade previstas nas diretrizes do PCCS-SUS 22.

Em Campinas não se criaram cargos multitarefas ou multiprofissionais, sendo definidos a partir das profissões ou especialidades. Em Guarulhos houve concentração nos cargos de especialista em saúde (nível superior), técnico de saúde (nível médio) e auxiliar em saúde (nível fundamental), mas estes não abarcaram todos os trabalhadores nos respectivos níveis de escolaridade e o total de cargos chega apenas a duas dezenas. Em São Paulo também se adotou a lógica dos cargos multiprofissionais, mas de maneira parcial, com a criação de quatro cargos: especialista em saúde (nível superior), especialista em saúde - médico, técnico em saúde e auxiliar técnico em saúde. Os três municípios não seguiram as diretrizes nacionais no que diz respeito à formatação dos cargos e privilegiaram a distinção dos profissionais médicos em cargos específicos.

Os princípios de compromisso solidário e avaliação de desempenho como processo pedagógico não foram contemplados nos PCCS analisados. Na progressão da carreira nota-se a centralidade do princípio da competição, pois nos três municípios há limites para a ascensão profissional, que varia de $5 \%$ a $30 \%$ em cada pro- cesso, sendo que em todos os casos a nota na avaliação de desempenho é critério de disputa das vagas de acesso.

Embora não haja menção específica ao tema nas diretrizes, os municípios adotaram prêmios por produtividade e desempenho que, no caso de São Paulo, pode elevar em até $100 \%$ o salário dos profissionais médicos. A inclusão do prêmio por produtividade e desempenho em São Paulo estaria vinculada à correção de distorções salariais internas ao sistema de saúde. Por sua vez, em sentido mais amplo, configura-se como mais um elemento a confirmar a incorporação de preceitos privatistas no seio do estado e, no mesmo sentido, ratifica a ideologia de ineficiência do serviço público e a suposta acomodação e desestímulo de seus trabalhadores 27 .

As diretrizes nacionais estipulam os critérios de mérito, tempo de serviço e escolarização para a ascensão profissional. Nesse aspecto notou-se uma assimilação seletiva das diretrizes, já que o tempo de serviço não assumiu valor central nos planos analisados, aparecendo apenas como critério de desempate nas avaliações.

Tópico de especial interesse no estudo, a gratificação ou adicional pela atuação na atenção básica, o que é previsto nas diretrizes, não apareceu nos planos municipais analisados: predomina a presença de adicionais em postos de difícil provimento ou acesso, bem como pela realização 
de plantões. Em São Paulo, a regulamentação da jornada dos profissionais médicos em "horaatendimento" explicita a noção de produtividade centrada exclusivamente na mensuração de procedimentos e cria óbices ao trabalho coletivo e ao aprofundamento dos vínculos com a população atendida.

É digno de nota a não menção, tanto nas diretrizes nacionais como nos PCCS analisados, a carreiras que abarquem cargos de gerenciamento no sistema de saúde, permanecendo estes estritamente vinculados à indicação do gestor municipal. Dessa forma, permanecem intocados os problemas da descontinuidade administrativa e da necessária profissionalização dos trabalhadores de nível gerencial.

Ademais, São Paulo e Campinas prevêem a duplicidade de punição aos trabalhadores da saúde em caso de suspensão, uma vez que a inexistência de tal penalidade é critério de aptidão para a mudança de categoria ou nível. Agregados, os instrumentos de sanção privativos dos níveis gerenciais e a participação gerencial na avaliação de desempenho podem subentender um alto grau de influência dos gestores sobre a ascensão profissional nas carreiras.

No que tange à educação permanente, não há menções específicas nos planos de Campinas e São Paulo. Guarulhos estipula em seu PCCS um programa de qualificação profissional e os gestores entrevistados mencionaram a proposta de criação de uma escola técnica do SUS no município. O programa de qualificação desse município faz referência à implementação do ensino a distância e à formação gerencial.

\section{Discussão}

Com base nos elementos anteriormente apontados é possível constatar a pequena adesão dos municípios aos princípios definidos pelas diretrizes nacionais do PCCS-SUS, a começar pela inexistência de PCCS em Ribeirão Preto, Marília e Santos - em clara afronta ao Termo de Compromisso de Gestão do Pacto pela Saúde.

Os municípios de São Paulo, Campinas e Guarulhos, além de adotarem práticas pouco democráticas no processo de construção e implantação dos PCCS, não demonstraram atenção a princípios como a equivalência e mobilidade, o que traz óbices às perspectivas de fortalecimento do SUS como sistema de saúde nacional, em que estão implicadas as três esferas de governo.

A análise dos PCCS anteriormente apresentados nas tabelas permitiu desenvolver a discussão que se segue, no que se refere às categorias e processos previstos na matriz apresentada na
Tabela 5, construída baseando-se nas formulações de Breilh e Granda 28.

Pelo que foi dado a observar considerando o relatório final da pesquisa que dá base para este artigo, há uma incipiente capacidade de gestão do trabalho na atenção básica dos municípios analisados, considerando-se os processos/categorias utilizados.

No que se refere à democratização das relações de trabalho, pode-se concluir que foi desconsiderada nos PCCS dos três municípios: a gestão partilhada de carreira, cuja concretude dá-se nas comissões partidárias de carreira, que não se efetivaram. A isso se alia o fato de que se as diretrizes nacionais consideram necessária a politização do processo de construção dos PCCS, como momento de participação social, nos municípios estudados os PCCS tomaram-no como uma questão técnica, a ser resolvida no âmbito gerencial, mediante contratação de assessorias especializadas. Não foram criadas nos municípios as comissões partidárias de carreira, visando a acompanhar e avaliar a implantação dos planos. O que mais se aproximou dessa arena foi a criação da Comissão Técnica de Gestão de Carreiras, em Campinas, a qual, porém, é composta exclusivamente por representantes dos gestores.

Na linha da ampliação de direitos enquanto vínculos públicos de caráter republicano, o que se observou no estudo no que se refere ao quantitativo de servidores na atenção básica, considerando as terceirizações especialmente no Programa Saúde da Família (PSF) e Programa Agentes Comunitários de Saúde (PACS) 29, foi uma postura, no que concerne à gestão de pessoal, que contraria aquela que vem ocorrendo a partir da década de 2000, no nível federal, em países como Brasil, Estados Unidos, Canadá e Austrália, onde se observa um aumento quantitativo de servidores civis concursados no aparato estatal 30

Por outro lado, quanto à contratação, observou-se a não realização de concurso público para estatutários na totalidade dos municípios estudados, no período da administração municipal que se encerrou em 2008. Aqui, o perigo pressentido baseia-se na afirmação de Ribeiro 31 “...a tendência é a flexibilização da regra do concurso público... mantendo a sua obrigatoriedade apenas para o preenchimento de determinados cargos...e tornando-o facultativo para o preenchimento de empregos públicos e para a investidura em alguns cargos públicos". Considera-se que, com isso, estaria havendo um retrocesso institucional com o retorno à situação anterior à Constituição Federal em vigor, pois o acesso com isonomia ao cargo público foi uma importante conquista da sociedade brasileira 31 . 
Tabela 5

Matriz analítica: processos, variáveis e indicadores de gestão do trabalho.

\begin{tabular}{|c|c|c|}
\hline Processo/Categoria & Variável & Indicador \\
\hline Democratização & Negociação & $\begin{array}{l}\text { Mesas de negociação; periodicidade; registro em ata; composição da mesa; processo } \\
\text { decisão (voto/consenso); representatividade }\end{array}$ \\
\hline $\begin{array}{l}\text { Direitos previdenciários e } \\
\text { sociais }\end{array}$ & Vínculo & Percentual de trabalhadores contratados por concurso público; processo seletivo etc. \\
\hline Contratação & Formas de contratação/Fixação & Porcentual de rotatividade \\
\hline Carreira/Emprego público & PCCS & Percentual de trabalhadores incluídos na carreira \\
\hline Progressão funcional & Modalidades de avaliação & Critérios de avaliação funcional \\
\hline Educação permanente & Formação/Capacitação & Percentual de trabalhadores com formação no período \\
\hline
\end{tabular}

Fonte: adaptado de Breilh \& Granda 28.

Na progressão dentro da carreira nota-se a centralidade do princípio da competição. Nos três municípios há limites para a ascensão profissional, que variam de $5 \%$ a $30 \%$ em cada processo, e em todos os casos a nota na avaliação de desempenho é critério para desempate na disputa pelas vagas disponíveis para acesso.

Outro aspecto relevante dos achados da investigação é a existência de PCCS em apenas três municípios, Campinas e Guarulhos e São Paulo a partir de 2006 - já que em Amparo data de 2003 -, situação esta que contraria os requisitos para a adesão ao Pacto pela Saúde e desestimula o ingresso de profissionais da saúde no serviço público. Nesse sentido, os baixos salários pagos pelo setor público são outro elemento que dificulta o “... exercício da função destes profissionais ante a inexistência, em grande parte dos municípios de um atrativo 'plano de carreira'" 31.

Quanto à atuação dos profissionais na atenção básica evidenciou-se que a maior rotatividade ocorre com os médicos, “... os quais aspiram ter sua carreira separada das demais categorias de trabalhadores e têm feito valer essa intenção em várias instituições" 32 (p. 160). Tal assertiva, de certa forma, corrobora a afirmação de representante sindical e dos trabalhadores de São Paulo entrevistada, para quem o PCCS de São Paulo teve como subproduto regular a atuação dos médicos e alguns privilégios que reivindicavam em relação aos outros profissionais da saúde.

Se a valorização do pessoal de saúde está intimamente ligada, como sugere a matriz acima, à sua capacitação e formação continuada, não se observou a existência de uma política específica de educação permanente como parte dos PCCS aprovados nos três municípios.

\section{Considerações finais}

Pelo que depreendeu-se da análise dos três PCCS estudados, seu enquadramento como instrumento estratégico para a qualidade de vida no/ do trabalho na atenção básica em saúde é limitado na medida em que várias lacunas foram observadas.

No que diz respeito à cobertura dos PCCS, observou-se que São Paulo e Guarulhos elaboraram planos destinados exclusivamente aos trabalhadores do SUS, enquanto Campinas aprovou plano que engloba trabalhadores de outros setores da Prefeitura.

Tendo como referência também a qualidade de vida no/do trabalho, outro aspecto importante é aquele relacionado à configuração dos cargos, visto que a homogeneidade e compatibilidade dos cargos nas diferentes esferas do poder público são condições necessárias para a efetivação dos princípios da equivalência e mobilidade previstos nas diretrizes do PCCS-SUS.

Coadunando-se com a perspectiva toyotista de organização do trabalho, coloca-se a possibilidade de funções e cargos "totipotentes", embora de maneira parcial e ainda associado às carreiras por profissões ou especialidades. Pensando-se a qualidade de vida no/do trabalho como possibilidade de crescimento e desenvolvimento de potencialidades do trabalhador, poder-se-ia considerar que os princípios de compromisso solidário e avaliação de desempenho seriam elementos que atuariam nesta linha, porém, como processo pedagógico, também parecem ter sido ignorados, ou afrontados, nos PCCS analisados.

Outro aspecto vinculado à qualidade de vida no/do trabalho é o relacionado ao nível salarial e a possíveis estímulos para seu aumento como abonos ou adicionais. A gratificação ou adicio- 
nal pela atuação na atenção básica, prevista nas diretrizes, não aparece nos planos municipais analisados.

Predominam os adicionais em postos de difícil provimento ou acesso, bem como pela realização de plantões. Em São Paulo, a regulamentação da jornada dos profissionais médicos em "horaatendimento" explicita a noção de produtividade centrada exclusivamente na mensuração de procedimentos, criando óbices ao trabalho coletivo e ao aprofundamento dos vínculos com a população atendida.

Por outro lado, se a qualidade de vida no/do trabalho aqui esposada pressupõe a participação democrática dos trabalhadores na gestão do cuidado dentro da atenção básica, observou-se que os três municípios, além de adotarem práticas pouco democráticas no processo de construção e implantação dos PCCS, não demonstraram atenção a princípios como equivalência e mobilidade, o que traz óbices à possibilidade de fortalecimento do SUS enquanto um sistema de saúde de caráter verdadeiramente nacional, em que estão implicadas as três esferas de governo.

Pensando-se a estratégia da qualidade de vida no/do trabalho também como ampliação de direitos, é digno de nota ressaltar a existência de PCCS em apenas três dos oito municípios estudados, situação esta que contraria os requisitos de adesão ao Pacto pela Saúde 20, além de desestimular o ingresso de profissionais da área da saúde no serviço público.
Se, a adoção de privilégios para determinadas profissões é algo que contradita a qualidade de vida no/do trabalho, do ponto de vista da atuação dos profissionais na atenção básica ficou patente que a maior rotatividade ocorre com os médicos, sendo observado que e o PCCS de São Paulo teve como subproduto regular a atuação dos médicos e alguns privilégios que estes reivindicam em relação aos outros profissionais da saúde.

Ademais, se quiser fazer-se avançar o projeto do SUS, aproveitando o momento político atual de escolha dos novos mandatários do Poder Executivo municipal em 2009, continua bastante válida a afirmação de Nogueira 30: "A efetividade da ação estatal está claramente a depender de um planejamento cuidadoso e de longo prazo da força de trabalho do setor público, que tenha um lugar destacado entre as políticas públicas".

Finalmente, pode-se afirmar, de forma preocupante, que são patentes as dissonâncias observadas anteriormente no que se relaciona à qualidade de vida no/do trabalho na atenção básica em sua articulação com a gestão do trabalho via os PCCS. A isso se soma a constatação de que as questões relativas à gestão do trabalho na atenção básica ainda são muito pouco apropriadas pelos Conselhos Municipais de Saúde. Elas passam ao largo de suas preocupações como foi possível constatar nas entrevistas com os representantes de usuários dos oito municípios estudados, matéria também de pouco domínio por parte dos dirigentes sindicais da saúde entrevistados, mesmo em municípios com maior tradição de luta no campo da saúde como Campinas, Santos e São Paulo. 


\section{Resumo}

O artigo trata do conceito de qualidade de vida no/do trabalho, articulando-o com a gestão do trabalho em saúde com base na avaliação de um instrumento de gestão do trabalho: o Plano de Carreiras, Cargos e Salários (PCCS). Objetiva-se analisá-lo como tecnologia de gestão do trabalho na atenção básica do Sistema Único de Saúde (SUS). São discutidos os PCCS de três municípios de São Paulo, Brasil: São Paulo, Guarulhos e Campinas, conforme diretriz emanada do Conselho Nacional de Saúde em 2006, mediante pesquisa de caráter qualitativo desenvolvida em 2007-2008. Retrata resultados de investigação realizada em oito municípios, considerando a visão do gestor, dos usuários representados nos Conselhos de Saúde e de sindicalistas e trabalhadores representantes dos trabalhadores de saúde que foram entrevistados. Conclui-se que a temática é incipiente como política pública de gestão, sendo matéria de pouco domínio seja dos usuários, seja dos sindicalistas e trabalhadores do setor saúde nos municípios estudados, situados dentre os mais populosos e "municípios-polo" de regiões de saúde.

Qualidade de Vida; Relações Trabalhistas; Sistema Único de Saúde

\section{Referências}

1. Lacaz FAC. Qualidade de vida no trabalho e saúdedoença. Ciênc Saúde Coletiva 2000; 5:151-61.

2. Mendes R. Doutrina e prática da integração da saúde ocupacional no setor saúde: contribuição para a definição de uma política [Tese de Livre Docência]. São Paulo: Faculdade de Saúde Pública, Universidade de São Paulo; 1986.

3. Bagnara S, Biocca M, Mazzonis DG. Trends in occupational health and safety policy in Italy. Int J Health Serv 1981; 11:431-50.

4. Roustang G. Os trabalhadores e a higiene e segurança na França. Revista Internacional do Trabalho 1983; 102:247-61.

5. Antunes R. Os sentidos do trabalho: ensaios sobre a afirmação e a negação do trabalho. São Paulo: Boitempo Editorial; 1999.

\section{Colaboradores}

F. A. C. Lacaz coordenou a investigação, elaborou a concepção teórica, participou da discussão, redação e revisão do texto. N. P. Vieira participou na elaboração, discussão e redação do texto. C. T. Cortizo e V. Junqueira colaboraram na discussão, redação e revisão do texto. A. P. L. Santos e F. S. Santos contribuíram no trabalho de campo, na discussão e redação do texto.

\section{Agradecimentos}

Agradecemos à Fundação de Amparo à Pesquisa do Estado de São Paulo (FAPESP) pelo apoio financeiro oferecido ao projeto de pesquisa que deu origem ao artigo. Agradecemos também à Regina Helena Petron Mennin pela orientação e discussão sobre grupo focal, à Maria de Deus de Oliveira Alves pelas contribuições, e à Michelle Franco Redondo e Jose Agnaldo Gomes pela realização de entrevistas.
6. Antunes R. Adeus ao trabalho? Ensaio sobre as metamorfoses e a centralidade do mundo do trabalho. São Paulo: Cortez Editora/Campinas: Editora da Unicamp; 1995.

7. Gorender J. Globalização, tecnologia e relações de trabalho. Estud Av 1997; 29:311-61.

8. Lacaz FAC. Saúde do trabalhador: um estudo sobre as formações discursivas da academia, dos serviços e do movimento sindical [Tese de Doutorado]. Campinas: Faculdade de Ciências Médicas, Universidade Estadual de Campinas; 1996.

9. Minayo-Gomez C, Thedim-Costa SMF. Incorporação das ciências sociais na produção de conhecimento sobre trabalho e saúde. Ciênc Saúde Coletiva $2003 ; 8: 125-36$. 
10. Lacaz FAC, Sato L. Humanização e qualidade do processo de trabalho em saúde. In: Deslandes SF, organizadora. Humanização dos cuidados em saúde: conceitos, dilemas e críticas. Rio de Janeiro: Editora Fiocruz; 2006. p. 109-39.

11. Marx K. O capital: crítica da economia política. Livro primeiro: o processo de produção do capital. v. I. Rio de Janeiro: Editora Civilização Brasileira; 1980.

12. Laurell AC, Noriega M. Processo de produção e saúde: trabalho e desgaste operário. São Paulo: CEBES/Editora Hucitec; 1989.

13. Laurell AC, editor. Para la investigación sobre la salud de los trabajadores. Washington DC: Organización Panamericana de la Salud; 1993.

14. Teixeira CF, Paim JS, Villasbôas AL. SUS, modelos assistenciais e vigilância da saúde. Inf Epidemiol SUS 1998; 2:7-28.

15. Lacaz FAC, Machado JMH, Porto MFS. Vigilância em saúde do trabalhador no Sistema Único de Saúde: diagnóstico inicial. Revista Brasileira de Vigilância Sanitária 2006; 2:112-21.

16. Cecilio LCO. As necessidades de saúde como conceito estruturante na luta pela integralidade e eqüidade na atenção básica. Rio de Janeiro: Instituto de Medicina Social, Universidade do Estado do Rio de Janeiro/ABRASCO; 2001.

17. Merhy EE. Saúde: a cartografia do trabalho vivo em ato. São Paulo: Editora Hucitec; 2002.

18. Franco TB. Reestruturação produtiva e transição tecnológica na saúde: um olhar a partir do sistema Cartão Nacional de Saúde [Tese de Doutorado]. Campinas: Faculdade de Ciências Médicas, Universidade Estadual de Campinas; 2003.

19. Departamento de Atenção Básica, Secretaria de Atenção à Saúde, Ministério da Saúde. Política nacional de atenção básica. Brasília: Ministério da Saúde; 2006. (Série A. Normas e Manuais Técnicos) (Série Pactos pela Saúde 2006, 4).

20. Coordenação Geral de Apoio à Gestão Descentralizada, Departamento de Apoio à Descentralização, Secretaria Executiva, Ministério da Saúde. Diretrizes operacionais dos pactos pela vida, em defesa do SUS e de gestão. Brasília: Ministério da Saúde; 2006.

21. Lacaz FAC, Vieira NP, Cortizo CT, Junqueira V, Santos APL, Santos FS. Avaliação da gestão do trabalho como tecnologia em saúde na atenção básica do Sistema Único de Saúde no Estado de São Paulo Relatório final. São Paulo: Secretaria de Estado da Saúde de São Paulo/Fundação de Amparo à Pesquisa do Estado de São Paulo; 2008.
33. Secretaria de Gestão do Trabalho e Educação na Saúde, Ministério da Saúde. Diretrizes nacionais para instituição de planos de carreiras, cargos e salários no âmbito do Sistema Único de Saúde. Brasília: Ministério da Saúde; 2006.

23. Brasil. Lei Federal no ${ }^{\circ}$. 8.080, de 19 de setembro de 1990. Dispões sobre as condições para a promoção, prevenção e recuperação da saúde, a organização e o funcionamento dos serviços correspondentes e dá outras providências. Diário Oficial da União 1990; 20 set.

24. Campinas. Lei Municipal no. 12.985 , de 28 de junho de 2007. Dispõe sobre o Plano de Cargos, Carreiras e Vencimentos dos Servidores do Município de Campinas e dá outras providências. Diário Oficial do Município 2007; 29 jun.

25. Guarulhos. Lei Municipal no. 6.359, de 3 de abril de 2008. Dispõe sobre a estrutura, organização e funcionamento da carreira e remuneração dos profissionais da saúde da Secretaria da Saúde do Município de Guarulhos. Diário Oficial do Município 2008; 4 abr.

26. São Paulo. Lei Municipal no. 14.713, de 4 de abril de 2008. Dispõe sobre a reorganização do quadro dos profissionais da saúde, a reconfiguração das carreiras dos níveis superior e médio do referido quadro e a instituição de novo plano de carreiras e do prêmio de produtividade de desempenho a ser concedido aos servidores que especifica. Diário Oficial do Município 2008; 5 abr.

27. Paula APP. Administração pública brasileira entre o gerencialismo e a gestão social. Revista de Administração de Empresas 2005; 45:36-49.

28. Breilh J, Granda E. Investigação da saúde na sociedade: guia pedagógico sobre um novo enfoque do método epidemiológico. São Paulo: Instituto de Saúde, Secretaria de Estado da Saúde de São Paulo/Rio de Janeiro: ABRASCO; 1986.

29. Marques AB. A terceirização da atividades-fim na área de saúde. Jus Navigandi 2003; 7(62). http:// jus2.uol.com.br/doutrina/texto.asp?id=3735.

30. Nogueira RP. Novas tendências internacionais da força de trabalho no setor público: o Brasil comparado com outros países. http://www.observarh. org.br/nesp/sistema/banco/20060503051944_nt_ versao_portugues.pdf (acessado em 15/Jan/2009).

31. Ribeiro AB. Vínculos de trabalho na administração pública brasileira. http://www.observarh.org.br/ nesp/sistema/banco/20061211073000_vinc_trab_ adm_pub.pdf (acessado em 15/Jan/2009).

32. Nogueira RP. Problemas de gestão e regulação do trabalho no SUS. Serviço Social e Sociedade 2006; 87:147-62.

Recebido em 19/Fev/2009

Versão final reapresentada em 27/Ago/2009

Aprovado em 10/Nov/2009 